\title{
Special judo fitness test level and anthropometric profile of elite female cadet judokas
}

\author{
Cristina CASALS ${ }^{*} 1,2$, Raquel ESCOBAR-MOLINA ${ }^{2}$, Yaira BARRANCO-RUIZ ${ }^{3}$, Jesús R. HUERTAS 1,2 \\ ${ }^{1}$ Institute of Nutrition and Food Technology - University of Granada (Spain) \\ ${ }^{2}$ Faculty of Sport Sciences -University of Granada (Spain) \\ ${ }^{3}$ School of Physical Culture - National University of Chimborazo (Ecuador)
}

\section{Introduction}

Judo is a weight-categorized sport, thus, the athlete must achieve excellent physical fitness while maintaining an optimal body mass. The anthropometric profile of judokas is, therefore, a relevant factor for success in competition and for performance in specific judo tests, such as the Special Judo Fitnss Test (SJFT) developed by Sterkowicz (1995). The anthropometric variables that best predict SJFT performance have been determined in elite Spanish judokas from senior and junior divisions (Casals, et al, 2015), but not in cadets. Thus, the aim of the present study was to assess the mentioned relationship between body composition and specific performance in elite female cadet judokas.

\section{Methodology}

A total of 12 female cadets from the Spanish National Judo Team were evaluated during a competitive period. All athletes underwent an anthropometric assessment through skinfold thickness measurements, following the protocol developed by the International Society for Advanced of Kineanthropometry. Anthropometric variables included body mass, height, 7 skinfolds (biceps, triceps, subscapular, supraspinal, abdominal, front thigh, and medial calf), 3 girths (upper arm flexed, thigh, and medial calf) and 3 breadths (humeral and femoral epicondyles and wrist).

Moreover, the athletes performed the SJFT, in which three athletes of similar body mass are needed: one participant (tori) is evaluated, and the other two (ukes) receive throws. The tori begins the test between the two ukes ( $3 \mathrm{~m}$ away from each uke). On a signal, the tori runs to one of the ukes and applies a throwing technique called ippon-seoi-nage (one shoulder throw)completing as many throws as possible within the test time. The SJFT is composed of three parts $(15,30$, and 30 seconds) separated by 10 -seconds recovery periods. The SJFT index was calculated as: Index= (Hear rate after + Heart rate 1 min after the test) / Total number of throws.

Linear regression analyses (stepwise method) were performed to explore the relationships between anthropometric variables and the SJFT index. Model 1 included body fat, muscle, and bone percentages as predictors. Model 2 included muscle leg and arm areas. The predictors of model 3 were somatotypes. Finally, model 4 analyzed quick-assessment variables, including skinfolds, breadths, girths, body mass, and height. All analyses were conducted using the SPSS statistical package; the level of significance was set at $\mathrm{p}<0.05$. Data is presented as mean \pm standard deviation. This study obtained ethical approval from the Research Ethics Committee of the University of Granada and was in accordance with the Helsinki declaration. 


\section{Results}

Model 1 showed that muscle mass percentage significantly predicted the SJFT index $\left(\mathrm{R}^{2}=0.70\right.$, $\mathrm{p}=0.001, B=-0.83)$. In model 2 , the arm muscle are was the best $S J F T$ predictor $\left(\mathrm{R}^{2}=0.62, \mathrm{p}=0.033\right.$, $B=-0.62$ ). Somatotypes were analyzed in model 3 , including endomorphy and ectomorphy in the predictor model $\left(\mathrm{R}^{2}=0.91, \mathrm{p}<0.001, B 1=1.46, B 2=0.68\right)$. Model 4 showed that the quick-assessment variable that best predicts the SJFT in elite Spanish female cadets is the biceps skinfold $\left(\mathrm{R}^{2}=0.60\right.$, $\mathrm{p}=0.001, B=0.82$ ). The cadet judokas achieved a SJFT index mean of $13.45 \pm 1.34$, body mass was $56.8 \pm 13.6 \mathrm{~kg}$, body fat was $18.3 \pm 5.1 \%$, and body muscle was $45.2 \pm 3.9 \%$. Somatotype mean (endomorphy, mesomorphy, ectomorphy) of elite Spanish female judo cadets was 3.22 \pm 1.40 , $3.34 \pm 0.94,2.68 \pm 1.31$.

\section{Discussion and conclusion}

The SJFT index mean can be classified as Regular according to the classificatory norms for female senior judoka (Sterkowicz-Przybycien \& Fukuda, 2014), therefore it was probably a good mean for cadets. Notwithstanding, to improve this judo-specific performance, our results showed that a higher muscle mass is associated with a better SJFT index in female cadets. Furthermore, it was especially relevant the arm muscle area compared with muscle leg; therefore, female judo cadets should increase their arm muscle mass improving their capacity to grip and perform explosive actions. Regarding to somatotypes, lower endomorphic and ectomorphic components were associated with a better SJFT performance; consequently, higher mesomorphic component is desirable in these judo athletes. Finally, according to previous results (Casals et al, 2015), the higher biceps skinfold was related to worse SJFT performance, explaining $60 \%$ of SJFT index variability. Summarizing, the anthropometric profile of female cadets from the Spanish National Team was significantly relevant for the specific-judo performance, then it is an important factor that should be considered during pre-competitive training programs.

\section{References}

Casals, C, Huertas, J.R., Franchini, E., Sterkowicz-Przybycien, K., Sterkowicz, S., Gutierrez-Garcia, C., \& Escobar-Molina, R. (2015). Special Judo Fitness Test level and anthropometric profile of elite Spanish judo athletes. Journal of Strength and Conditioning Research; Epub ahead of print.

Sterkowicz, S. (1995). Test specjalnejsprawnoscituchowej w judo. Antropomotoyka, 12-13, 29-44.

Sterkowicz-Przybycien, K.L., \& Fukuda, D.H. (2014). Establishing normative data for the Special Judo Fitness Test in female athletes using systematic review and meta-analysis. Journal of Strength and Conditioning Research, 28(12), 3585-3593.

Key words: Sports performance; body composition; Judo; martial arts; combat sports; SJFT.

Study supported by the Consejo Superior de Deportes - Ministerio de Educación y Ciencia [Higher Council of Sports, Spanish Ministry of Education and Science] (33/UPB10/10). 